\title{
LEARNING TO SUPPORT LEARNING TOGETHER: AN EXPERIENCE WITH THE SOFT SYSTEMS METHODOLOGY
}

\author{
Adolfo Sánchez \\ Learning Support \\ Colegio Anglo Colombiano \\ Avenida 19 No. 152 - 48 \\ Bogotá, Colombia \\ Tel: (57 1) 2595700 Ext. 182 \\ E-mail: adosanc@gmail.com
}

\author{
Andrés Mejía D. \\ Departamento de Ingeniería Industrial \\ Universidad de Los Andes \\ Carrera 1 No.18A-10 \\ Bogotá, Colombia
}

Tel: (57 1) 3394949 Ext.3099

E-mail: jmejia@uniandes.edu.co

\begin{abstract}
An action research approach called Soft Systems Methodology (SSM) was used to foster organisational learning in a school regarding the role of the Learning Support department within the school and its relation with the normal teaching-learning activities. From an initial situation of lack of co-ordination as well as mutual misunderstanding and distrust among some of the actors in the situation, 8 months of work yielded as a result a better working environment among the participants, the creation of a volunteer discussion group functioning on a permanent basis, and a clarification and modification of some of the Learning Support activities. This change can also be described as a learning by Learning Support staff, school teachers and administrators, on how to work together, as well as on how to support children's learning in a better way. Nevertheless, a further change that occurred after the intervention, shows the importance of considering a wider system than that limited by the participants in the intervention.
\end{abstract}

$\underline{\text { Keywords: }}$ soft systems methodology, learning support, organisational learning, trust, action research

\section{Introduction}

Participatory Action Research (PAR) can be seen as a means of doing research that attempts to be socially relevant by involving stakeholders in a problem situation, in the production of practical knowledge that drives real changes in that situation (Reason and Bradbury, 2001). This paper reports on an application of a form of PAR, based on Peter Checkland's Soft Systems Methodology (SSM) (Checkland, 1972 and 1981; Checkland and Scholes, 1990), in a Learning Support department that serves the secondary level (grades 6 - 11) in an international school in Bogotá (from now on, LS). The project involved assembling a research group comprising both LS staff and teachers from the secondary school, and working with them through the stages of SSM in weekly or fortnightly meetings during a period of eight months. Work with the methodology consisted, roughly, in getting to appreciate a number of different worldviews, or weltanschauungen, to inquire into the situation from them, and to ultimately agree on 
actions to improve the situation and implement them. All in all, we wanted to answer research questions related to three different dimensions, summarised in the following: 1) how does LS change organisationally -in terms of its capacity to be a learning organisation, and in its relations with other actors of the situation - as the process develops?; 2) how does LS change in the way it carries out its pedagogical activities, as the result of the process?; and 3) what impact is produced on the students - in terms of their academic performance, wellbeing, and learning autonomy - as the result of the process?

To this end, in section 2 we describe the initial problem situation, as well as provide a brief description of the context in which the intervention took place. Section 3 explains the methodology used, SSM, in its pure theoretical form. In section 4 we describe the actual process, accounting both for the methodological steps followed and for the results obtained. In section 5 we present and discuss these results, in three dimensions: organisational, pedagogical, and of students' learning. Finally, section 6 consists of some discussion about the significance of our work

\section{A description of the initial situation}

LS offers a special service to students with Learning Disabilities (LD). In one-to-one sessions, it gives students personalised lessons to help them improve academically during school time, and guarantees Exams Special Arrangements to some of them according to their LD. There are three permanent staff working in LS at the secondary school level, one of whom is the director. One of the authors of this paper works at LS, but also was a member of the group of participants who used SSM in this project.

There were very polarised opinions about LD and the role of LS in the school, and many teachers were against the way LS helped the students. Some of them did not like the idea of letting their students off class to go to LS, and others saw exam arrangements as unfair advantages. All this generated a big controversy about the role of LS in the school and produced a huge tension between LS and the teachers. By the end of the exams in June 2004 the Director of the Mathematics Department criticised the Exams Special Arrangements offered by LS. She questioned the criteria used to decide who should receive special arrangements and said that LS had reduced the fairness of the tests.

At the end of the year 2004, LS was facing many problems: Its relationships with other school members were not harmonious, its administrative processes were not efficient, and the support sessions were often used to solve just urgent issues. Thus, the students were not receiving a systematic support according to their LD. Many people pointed out what they considered problematic in LS, but there was not agreement on what the real problem was or what the solution could be. In other words, a messy problem situation was being faced, rather than a well-structured problem (Ackoff, 1978). 
At the beginning of the year 2005, the LS members decided to use action research to improve the department in order to offer a better service to the students. Given that they had neither a well-defined problem nor an agreement on the possible solution, they chose SSM as the methodology that would guide the process. Their purpose was to learn as much as possible about the problem situation and take concrete actions to improve it based on the knowledge generated during the learning process. They wanted LS to enter into a Learning Cycle.

Our first challenge was to consolidate a group of teachers representing all the positions within the school. It was a difficult task because some teachers just did not want to know anything about LS. Furthermore, it was very difficult to create the appropriate environment in which everyone's opinion could be safely expressed, enhancing the relationships among the participants instead of menacing them. There were contradictory perspectives on LD and what the role of LS should be in the school.

\section{Overview of the Soft Systems Methodology}

The Soft Systems Methodology, or SSM in short, was proposed by Peter Checkland and his team at Lancaster University (Checkland, 1972, and 1981; Checkland and Scholes, 1990). It is a systemic methodology designed to tackle problem situations of a messy and complex nature; that is, situations involving a relatively large number of relevant aspects, in which the problem cannot be defined in a unique uncontroversial way, and there is a number of different views about it held by different actors. SSM is systemic in a double sense: It uses systems ideas in order to inquire about a problem situation; and the methodology itself can be seen as an inquiring system. In our interpretation, it is based on the following fundamental principles:

- The way humans see problem situations in the world is unavoidably influenced by their worldviews, or weltanschauungen. Each weltanschauung focuses on some aspects of a situation, but ignores others, and in this sense it is partial.

- Problems in a problem situation are related to particular weltanschauungen. That is, where someone sees a problem, someone else may not.

- Systems tools can be used as conceptual frames that help articulate weltanschauungen relevant for a situation. Systems are constructed in people's minds to (partially) make sense of complex situations; but they are not "the real world". (In order to avoid confusion with the realist everyday language notion of "system", the term "holon" is normally used; see Checkland, 1988 and 1995.)

- Various holons expressing weltanschauungen relevant to the actors involved in a problem situation must be explored and discussed by them. This way, learning both about the problem situation as well as about other actors' views will occur. 
- The purpose of the methodology is not optimisation -that is, finding an optimal solution to a problem. Rather, it is to produce learning that will lead to improvement in the problem situation (according to the criteria formulated by the various actors involved, and derived from their weltanschauungen).

- Given that the problem situation is ever changing, just like the actors' views of it, the methodology is cyclic and therefore has no "stopping rule".

Even though the methodology has been developing throughout the years, it is most widely known and used in its so called 7-stage version (Checkland, 1981). This version is actually the one our activities most closely approached, and we will now present it. Nevertheless, a few modifications were introduced in its application, which we will make explicit in section 4 of this paper. The following is a diagram representing the 7stage version:

\section{\{Insert figure 1 here $\}$}

Stage 1 consists of a delimitation of the problem situation that will be considered. It simply requires us to define what it is that will be explored. Care must be taken in order to avoid defining a problem from the start: It is a problem situation that participants will learn about, and not a problem that they will solve. If a problem is defined from the start, participants will have been forced to adopt a particular weltanschauung, thus ignoring others.

Stage 2 is devoted to expressing a multiplicity of aspects of the problem situation, in detail. No coherent or consistent picture of the situation is needed at this stage; rather, emphasis must be put on detail and completeness, in order to allow for a number of different holons to be later extracted from it. Rich pictures are usually used here to convey the description, given that, according to Checkland and Scholes (1990), some issues may be more easily expressed by this means as compared with doing it in writing.

In stage 3 a number of holons is formulated that articulate the various ways in which sense can be made of different aspects of the problem situation, which are felt relevant by the actors in the situation. These holons are not necessarily descriptions of (a part of) the situation, nor declarations of what it ought to be. In fact, we take it that the complexity of social situations is likely to render any such holon untrue if it were taken to be a description of the situation. Holons are always, at least in this sense, partial. Each holon is expressed through a root definition, and its corresponding CATWOE. A root definition declares a holon as a system doing something $(\mathrm{X})$, using some means $(\mathrm{Y})$, in order to achieve some purpose (Z). The CATWOE can complete the description by adding some elements: Clients, Actors, Transformation, Weltanschauung, Owners, and Environment. It has been found helpful to distinguish between holons that declare activities and purposes that one would expect to find in official catalogues and 
declarations (such as mission statements), and holons that declare polemical activities and purposes that it may be relevant to explore. Checkland has called them, respectively, task-based and issue-based (1981). Nevertheless, given that practically all activities and purposes can appropriately be thought of as tasks, we prefer to use the expressions official and non-official.

Stage 4 is the construction of conceptual models. A conceptual model is always associated to a holon, and it depicts the activities required if the holon were to be fully implemented. In general, for each holon one conceptual model is made. These models, together with stage 3's CATWOEs, explore the implications and consequences of each of the holons proposed as relevant for discussion. Checkland further suggests that any systemic models can be used here to boost this exploration.

Stage 5 compares the holons with the real world, in search for matches and differences. Given that holons have captured what is relevant for the actors involved in the situation, they must be used now to inquire into how the real-world situation is in that respect.

In stage 6 proposals for action are formulated as a result of the discussion in stage 5 . Additionally, these action proposals are said to have to comply with two requirements: They must be systemically desirable, and culturally feasible. The first requirement tries to ensure that all the actors' concerns explored in the holons through stages 3 to 5 are dealt with holistically.

Stage 7 corresponds to the implementation of the actions agreed upon in stage 6.

All in all, in our interpretation the general attitude of stages 1 and 2 is one of alertness for new aspects that might be relevant for the situation. In stages 3 through 5 the attitude is perhaps more oriented towards a deep understanding of other people's worldviews and viewpoints about the situation, exploring their implications and consequences. In stage 6 the attitude needs to be conciliatory and creative in order to find solutions to the possible conflicts that may arise between the implications of different worldviews. Lastly, in stage 7 the attitude must be entrepreneurial.

\section{The process}

During the process the participants enriched their perceptions of the problem situation through exercises that allowed them to know each other's points of view. They compared the different perceptions of LS and identified the areas that must be improved in order to make it a better organisation. The number of participants in every stage varied from 16 to 9 teachers. 
We chose to be flexible in following the stages of SSM, in order to foster confidence inside the group. For example, rich pictures served more as means to expressing feelings and perceptions difficult to communicate, than as detailed descriptions of the problem situation. The relationships among the group members evolved in a very positive way, allowing them to openly discuss harsh subjects in a constructive atmosphere.

\subsection{I nitial agreements and delimitation of the problem situation}

The participants received an introduction to the SSM and decided to meet once per week to work on the different steps of the SSM. They made explicit their intention to learn as much as they could about LS instead of trying to define and solve a particular problem.

\subsection{Rich Pictures}

They expressed their perception of the problem situation by means of cartoon-like drawings. Figure 2 shows an example.

\{Insert figure 2 here.\}

The author of this picture explained that the lion represents LS protecting its cubs. These cubs are happy when they are in LS, but their mood changes when they are in the classroom. The arrows represent the relationships: Strong and healthy between LS and the students, weak between LS and the teachers, and strong but unfriendly between students and teachers. The teachers are divided in three groups: the invisibles, the evils that bother the students and the ones who are ready to listen to the students. The whole purpose of everybody is to ensure that the students can obtain satisfactory grades (4 and above).

Some additional ideas expressed during this step were:

- $\quad$ LS isn't promoting the students' autonomy; instead, it generates dependency.

- $\quad$ LS overprotects the students and tries to do everything for them.

- $\quad$ LS effort mustn't replace the students' effort.

- $\quad$ LS doesn't have a good communication with other departments.

- $\quad$ LS wants to do so many things that it ends up doing everything without quality.

- $\quad$ LS doesn't work co-ordinately with other school members.

- $\quad$ LS doesn't work according with the school principles.

- $\quad$ LS helps the students get acceptable grades but it doesn't teach them to learn.

- $\quad$ Students miss what they should learn in class when LS takes them out of class.

- $\quad$ LS doesn't inform the progress of its students.

- $\quad$ LS should be a temporal scaffolding for the students, not a permanent crutch.

- $\quad$ The three sections of LS (pre-school, primary school and secondary school) don't work co-ordinately. 
- $\quad$ LS should consider the students' emotional issues while they are supported.

- LS has two faces: one is an administrative mess and the other one makes the students happy.

- $\quad$ Students like LS because they can go there to take a rest and sleep.

- $\quad$ LS should develop individual strategies for the students depending on their learning styles. For this reason LS must know well all the students.

- LS helps some students that don't need to be helped, and doesn't help some students that really need to be helped.

The teachers expressed their feelings and made important suggestions; some of them also made harsh comments. This step was very useful because LS knew how the teachers perceived its work and opened a communication channel with them.

\subsection{Formulation of the Holons and use of the CATWOE}

Each participant was asked to identify two different transformations made by LS: one official and one non-official. For each transformation the remaining elements of the CATWOE (clients, actors, weltanschauung, owner, and environment) were also identified, and they were summarised in root definitions.

The official versions were very similar. They state that LS is a system whose clients are the students with LD, and the actors are the LS specialists. Its objective is to help the students to overcome their academic difficulties through a co-ordinated work with teachers and parents. The main restrictions are time and budget. The owners of the system are the school directives and the parents. On the other hand, there was a great variety in the non-official versions. For example, LS was seen as a crèche as well as an instrument to relieve the parents who do not dedicate much time to their sons and daughters. It was also deemed an aid for the students to learn what they could not learn in class, and at the same time as the department that thwarted their learning by creating unreal situations where they get everything without any effort. Other non-official definitions included a department that gives the students all the answers without any effort on their part, a service for teachers who want to get rid of their students during their classes, and a tool to recognise those students who leave the school due to learning disabilities. It was interesting to note that even having the same actors, the different relationships among them produce very different systems.

In this stage, three main possible objectives were identified for LS: 1) to ensure the students' wellbeing, 2) to improve the students' academic performance, and 3) to promote the students' autonomy.

\subsection{Conceptual Models}


The participants made a list of the required activities to carry out the transformations identified in the previous steps. Then, they connected those activities following a logic order, so we could identify the critical steps for each transformation. The non-official versions allowed for the identification of three possible causes for the main problems in LS: failures in the admission to LS process, imprecise definition of the type of support that each student needs to receive, and poor communication between LS and the teachers.

The official versions, as in the previous steps, were very similar. The official models were used to construct the general model of LS that, based on the three main purposes defined for LS (see section 4.3), comprised three main processes: knowing the student, supporting the student, and saying good bye to the student. The conceptual model of the whole LS system and of one of its subsystems are depicted in figure 3.

\{Insert figure 3 here.\}

The general model of LS includes three main processes: knowing the student, supporting the student, and saying goodbye to the student. This figure shows some details of the knowing the student process.

\subsection{Models compared with reality}

The participants studied in detail the activities identified for each model, and discussed whether the activity existed, how it was done, who was in charge of it, and whether it was a good or a bad thing with respect to the purposes defined for LS. They also proposed alternatives for each activity.

These are some ideas that emerged during this step:

- $\quad$ The school must establish clear policies for LS.

- $\quad$ The results of the support must be evaluated.

- Teachers must get involved in the identification of the students' LD.

- $\quad$ Parents and teachers need information on LD.

- $\quad$ The recommendations that LS gives to the teachers must be clear and realistic.

- The school should hire a person to diagnose the students in the school.

- $\quad$ Some students should be sent to external support.

- $\quad$ LS must define clearer criteria to decide which students will be supported.

- $\quad$ LS must work co-ordinately with teachers and parents to offer a better support.

- $\quad$ Students receiving support should not be released from all their responsibilities.

- LS must clarify and communicate the services it offers, in order to avoid misunderstandings.

\subsection{Desirable and feasible changes}


As a result of the previous steps, various needs were identified such as to improve the LS relationships with the teachers, to align its objectives with the school's, and to implement more efficient processes. As a result, it was decided to establish periodical meetings to work on administrative issues and to create a discussion group to address pedagogical topics.

\subsection{Action implementation}

Currently three administrative weekly meetings take place, which are direct products of the project:

- Objective Alignment Meetings between the Head of Secondary and the LS director to align LS with the school requirements,

- General Model Meetings to review the LS administrative processes with the LS staff, and

- $\quad$ Meetings with the PSHE-Heads to ensure a permanent communication between them and LS.

A discussion group was also created. Once per week, teachers and some LS staff members discussed subjects such as LD, multiple intelligences and constructivism. The idea was to read two articles during the week, each one presenting the same subject from different perspectives, and then have a discussion based on those articles. During these discussions each participant could advance in the construction of his/her own knowledge of the topics addressed. New inquiries about particular subjects made us widen the background theory for our PAR and the results generated at this level served as evidence to solve the main questions of the inquiry.

In terms of the LS activities, a process of self-observation at the micro level was started, in order to improve the way LS led its support sessions with the students. The object of analysis here was the interactions between LS staff and students. For this reason, the internship student observed some support sessions using a guide designed to assess LS' progress in its pedagogical activity. This exercise allowed them to recognise themselves as members of an organisation that is learning to support learning. Nevertheless, the exercise was limited and put in evidence one of the main weaknesses of this PAR in its attempt to involve everyone: one of the LS specialists did not allow the internship student to be with her during the support sessions because she did not want to be observed. As a consequence of this, there is little information about the pedagogical practices used in her support sessions.

\subsection{Later events}

When we were about to finish the writing of this paper the LS director was asked to leave the school because the LS department will be re-structured. Despite the positive changes within the group of participants, the relationships among the LS director and 
other members of the school who were not involved in the intervention reported here because they do not interact with LS in a regular basis - remained tense. Although we do not know this with certainty, there are reasons to believe that these continuing tensions may have precipitated the re-organisation of LS.

\section{Data collection}

During the implementation of the steps of SSM, all the information generated by the participants - such as root definitions, conceptual models, and so on - was collected while they were going through the seven stages of the SSM. This information was useful to learn both about the changing problem situation itself, and about the changing participants' perceptions of LS and the relations between them. At the end of this period, the teachers, LS staff, Head of Secondary and twelve students were interviewed to know their perceptions about changes in LS and in its relation with other members of the school. During the last two months, the internship student who was working in LS observed fourteen support sessions. During the whole process, a journal was kept in which field notes were taken concerning anything that seemed to be relevant to the research questions. The interviews, field notes, products of SSM, and support session observations, effectively constituted a set of different sources that helped triangulate and validate the results.

\section{Results and discussion}

From a rationalistic point of view one would say that it is in the implementation step of SSM (step 7) that new results are produced. Nevertheless, it is actually during the whole process that social relations change and learning takes place, and these should be considered results in themselves. In line with our research questions, we have classified the results in 3 categories: organisational changes in LS, pedagogical changes in LS, and impact of these changes in LS on the students.

\subsection{Organisational changes in LS: How does LS change organisationally as the process develops?}

The Objective Alignment Meetings and the General Model Revision Meetings produced the main organisational changes in LS. We focused our attention on the LS role and its alignment with the school objectives as well as on LS relationships and processes.

Is the LS role clearly defined?

Three points concerning the purpose of LS generated controversy when its role was being defined: academic performance, wellbeing, and autonomy of the students. The main achievement was to start seeing how closely related those points are. The 
participants understood that the wellbeing of the students depends on their academic success, and their academic success depends on their autonomy. Nevertheless, the interviews show that the different opinions still persist. In a discussion, a teacher insisted that "LS should focus on teaching how to survive in the school without being supported" while another said that "above all, LS must make the students happy".

All the teachers interviewed said they know what the LS role is. Nevertheless, some of their answers were not precise when asked to describe it. In general, they said that LS should "help students with LD", but it was not clear how the students should be helped. LS is clarifying its role, trying to accommodate the different requirements of the school, but still needs to work on this point to establish it in a precise way, and then communicate it in a clear manner.

\section{Is LS aligned with the school objectives?}

11 of the 14 teachers interviewed consider that LS is now more aligned with the school than before, but they also said that this alignment process must continue. Some support programmes were established or modified according to the expectations of the school, such as Support in the library for fifth graders, LS instead of French, and Inclusion. (In Support in the library for fifth graders, the LS specialists help the weak students during their weekly visit to the library. In LS instead of French, the student goes to LS when his/her classmates are taking French. In Inclusion a LS specialist supports the student in class, instead of taking him/her out of class.) The perceptions about the new programmes are good, even though they still need to be improved. Only 4 of the 14 teachers interviewed said they had received a LS specialist in their classes for the Inclusion programme. Just a couple of students are officially in LS instead of French, and Support in the Library is based on the IOWA Test's results, not on the students' LD.

How are the relationships between LS and the teachers changing?

LS aims to improve its relationships with other school members by improving its communication with them. For this reason, the LS director established a weekly meeting with each PSHE - Head of Year - to discuss the students' Individualised Educational Plan (IEP). Additionally, some differences among terms used in LS were established, such as recommendations, accommodations, modifications and strategies, in order to prevent misunderstandings that may harm the relations between LS and the teachers.

During the interviews 12 teachers said that they perceived a positive change in their relationship with LS. One of them said that the main achievement of the PAR was "to have created awareness of LS in the school". Another important achievement was the improvement in the relationship between the LS director and the Head of Secondary. Both said in their interviews that they enjoyed a better communication. Although it is hard to assess the significance of the recent event concerning the departure in the near future of the present LS director, we think that it has some important implications for 
our conclusions concerning this point. We will discuss this issue in the last section of this paper.

\section{Are the LS processes efficient?}

Three main processes were defined in LS: knowing the student, supporting the student, and saying good bye to the student. The first includes the admission process and the last refers to the stage where the student doesn't need to be supported anymore. So far, work has concentrated on the first two processes; the last one has not been implemented yet.

The admission process to the support programme is more rigorous. Now, only students with a psycho-pedagogical evaluation that confirms their LD or any weakness are accepted in LS. The LS director said that the renovated rigour in the admission process increased confidence in LS. As evidence for supporting this perception, she mentioned that last year the Head of Secondary approved just a few IEPs because he did not agree with most of them, while this year he approved almost all the IEPs. Nevertheless, the Head of Secondary said that he still has some differences with the LS director in relation to the criteria used to decide which students should be in LS.

LS is doing an IEP for every student. Today, 93\% of the students already have an IEP, and $82 \%$ of them are already approved by the Head of Secondary. This has made the support process more efficient, because the students are helped according to their particular needs. The exam arrangements have been reduced in quantity but increased in quality. The number of students receiving special arrangements was reduced from 81 last year to 34 this year. Now, LS offers those arrangements only to students who really need them. In contrast, the arrangements will be offered during the whole academic year, not only during the final exams.

LS also changed the way of informing the teachers about the students who are in the support programme and how can they be helped in class. The volume of the information and the format used last year were inadequate. A teacher said that when he received too many sheets of paper with a very complicated language he preferred just to throw them away. Now, every teacher receives a list with four recommendations for each LS student. In the interviews, all the teachers said that they considered this new way of receiving the recommendations useful and easier to use.

\subsection{Pedagogical changes in LS: How does LS change in the way it carries out its pedagogical activities, as the result of the process?}

LS decided to encourage the students to play a more active role in the construction of their own knowledge and support them according to their learning styles. In order to facilitate this, the LS specialists designed and filled-in a format with the most relevant information of their students: diagnostic statement, learning style and learning objectives. 
The observations confirmed that the students are being supported according to their characteristics and are also being encouraged to construct their own knowledge instead of just receiving information. An example of this is the fact that a LS specialist used chips to teach the students how to add and subtract, letting them to do the operations by themselves instead of just giving them the answers of the exercises. This is a shift to pedagogical practices more consistent with constructivist principles, even though this was never established as one of the objectives of this project. The observations of the support sessions showed that the students are working more by themselves and ask for help just when they really need it.

\section{Do the LS specialists know the IEP of their students?}

In 12 of the 14 observations of the support sessions the LS specialists knew the diagnostic of the student and in 13 they knew the learning style and the objectives of their students. The interviews confirmed this information. The LS specialists said the format with the most relevant information about the students is very useful.

\section{Do the LS specialists support their students according to their IEP?}

The observations of the support sessions suggest that the LS specialists base those sessions on the IEP of their students. In 12 of the 14 observations the LS specialists supported the students according to their learning styles. Nevertheless, the observations and the interviews with the LS specialists showed that the use of resources during the support sessions is limited.

\section{How much time of the support sessions is used to solve urgent issues?}

One of the most visible changes is the tendency to avoid using the support sessions to solve urgent issues of the students. Now, the support sessions are used to work according to the IEP and not to finish the assignments that the students did not do at home. During the interviews the LS specialists mentioned the example of the student who complained because "LS isn't the same. Now I can't come to print out my homework. That was the best of LS!" (our translation).

\subsection{Changes on the students: What impact is produced on the students as the result of the process?}

We believe that ultimately the organisational and pedagogical changes in LS can only be measured in terms of the positive impact that they have on the students. For this reason we decided to analyse the impact on the three areas defined as the LS objectives: academic performance, wellbeing and autonomy of the students. Nevertheless, until now we still do not have precise indicators to measure this impact. The results are based on the perceptions on these issues held by the teachers, the LS staff, and a group of twelve students. 


\section{Academic performance}

The grades did not show a significant change in this aspect. Nevertheless, 8 of the 14 teachers who were interviewed asserted that the students who received support had improved their academic performance. Those teachers said that they noticed more organisational skills in their students as well as more punctuality handing in their assignments. The other six teachers, however, said they had not noticed any progress, and one of them mentioned a particular case where the problems persist. There is no evidence to categorically assert that LS students have improved their academic performance as a result of the process.

\section{Wellbeing}

This point is very difficult to measure. Nevertheless, only 2 teachers said in the interviews that they did not notice any change in the students' wellbeing. The other 12 teachers manifested to have noticed a big rise in the self-esteem level of those students who are being supported. The students interviewed said that they feel more secure in the school knowing that they can count on LS.

\section{Autonomy}

Unfortunately, we could not find enough evidence to assert there were significant changes in the students' autonomy level. Nevertheless, during the interviews the Head of Secondary said about one of his students that "he is less dependent. He is more responsible and now he doesn't blame the others for everything that happens to him." In a focus group, 8 teachers said that they perceived some progress in their students' autonomy, but none of them had concrete evidence to support it. LS needs to work a lot to obtain significant results in this point.

Despite the difficulty in obtaining clear evidence of improvement in these respects, we think that the achievements so far are very encouraging - especially if we take into account that we only looked at the impact in a very short term.

\section{Concluding remarks}

Participatory Action Research has been said to be a research approach that attempts to be socially relevant, producing an impact on the actual problem situations it is carried out in, with the involvement of those concerned with the situation. Popular wisdom about this approach would further say that new - in some cases tacit - knowledge is gained by means of a reflexive engagement with the action aimed at improving the problem situation. We also think that this is the case. Nevertheless, we have tried to show in this paper that it is not only new practical knowledge about the problem situation that can be gained, but also new practical knowledge about how to work together, either generally or specifically towards its improvement. In this sense, with this project we have shown that the use of PAR can potentially have a positive impact on 
organisational learning. We do not know with precision the extent to which the particular choice of SSM as the guiding methodology could have influenced this result; but we think that its emphasis on the articulation and appreciation of multiple perspectives was particularly important for overcoming the environment of distrust that initially characterised the situation. This lesson was learned in a very positive way as there was an actual improvement, at least in the pedagogical and organisational dimensions of LS. The scope of this project was too small to be able to assess with clarity the ultimate impact on students. The other great lesson was learnt in a negative way, though, as a possibly bad event took place that the intervention was not able to avoid. The importance of whatever we leave out of our designed or intervened-upon system, or whatever is the case, became apparent when the LS director was asked to leave the school. With hindsight, we now believe that this event could have been handled in a better way, had the participatory group included other relevant actors within the school. In systemic terms this means to broaden the system borders, in order to include more participants, resources, or, generally, more elements for consideration. But these system borders cannot be infinitely broadened so as to include everything - because that simply lies outside the human capacity - and a choice will always have to be taken (Churchman, 1968; Ulrich, 1983; Midgley, 2000). In some cases, such as the one we report here, the relevance of some elements belonging to the system's environment will only become apparent once they have already affected the situation. In this sense, it is only then that those elements become real in our knowledge of the situation - or of situations, generally (Mejía, 2002). But the realisation of this can be called learning, and is one of the goals behind any PAR-guided intervention.

We take the two dimensions that correspond to the lessons just referred to, to suggest possibilities and limitations of interventions guided by PAR. Nevertheless, they should not be seen as exclusive of PAR, but as a characteristic of the complex nature of social affairs. Given the impossibility of isolating a set of variables that can fully explain some social phenomenon - regardless of the research approach used (Checkland, 1981) - it is always possible that the relevance of new aspects or elements not previously taken into account will only become apparent after the fact. But still we think that the project reported here supports the idea that the purposes of creating the conditions for the stakeholders to work together to improve the problem situation, and of ever widening the system borders under consideration, are well served by a PAR methodology such as SSM.

\section{References}

Ackoff, R. (1978). The art of problem solving (New York, Wiley).

Checkland, P. (1972). Towards a systems-based methodology for real-world problem-solving. Journal of Systems Engineering, 3(2).

Checkland, P. (1981). Systems thinking, systems practice (Chichester, Wiley).

Checkland, P. (1988). The case for "holon". Systems Practice, 1(3), 235-238. 
Checkland, P. (1995). Model validation in soft systems practice. Systems Research, 5(1), 47-54. Checkland, P. and Scholes, J. (1990). Soft Systems Methodology in action! (Chichester, Wiley).

Churchman, C. (1968). The systems approach (New York, Dell).

Mejía, A. (2002). To what extent is the system idea useful for understanding the act of knowing? In the proceedings of the 46th annual meeting of the International Society for the Systems Science (ISSS), Shanghai, August 2002.

Midgley, G. (2000). Systemic intervention: Philosophy, methodology, and practice (New York, Kluwer).

Reason, P. and Bradbury, H. (2001). Inquiry and participation in search of a world worthy of human aspiration, in P. Reason and H. Bradbury (Eds.), Handbook of action research: Participatory inquiry and practice (London, Sage).

Ulrich, W. (1983). Critical heuristics of social planning: A new approach to practical philosophy (Berna, Verlag). 
1. Real-world situation considered to be problematic

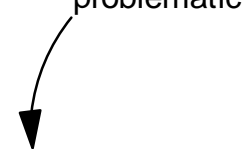

2. Problem situation expressed (by various means, including rich pictures)

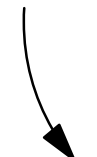

3. Formulation of relevant holons with root definitions and CATWOES

7. Implementation of

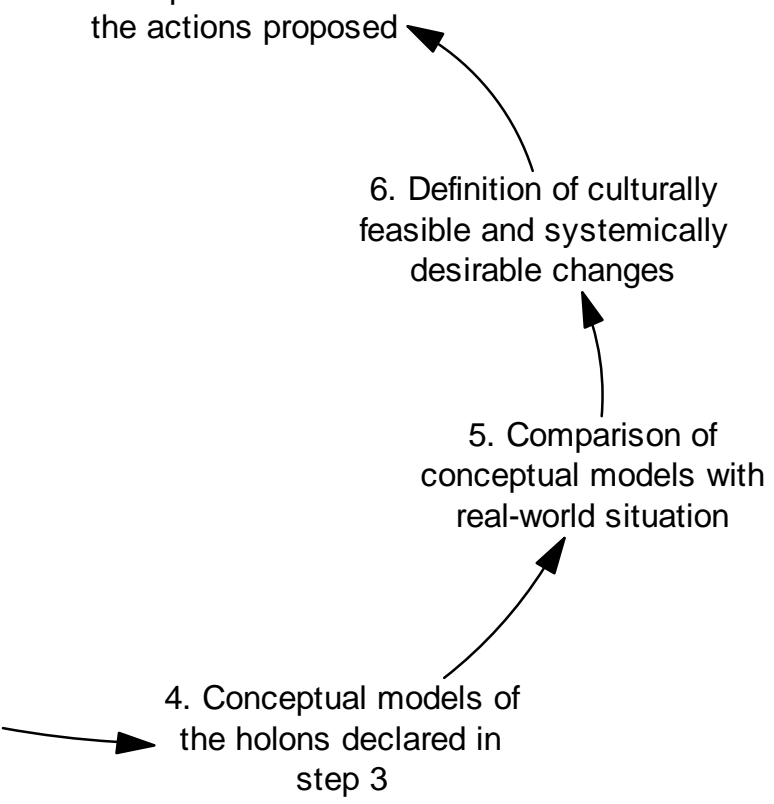
the actions proposed

Figure 1. 7-stage version of SSM. Adapted with modifications from Checkland, 1981. 


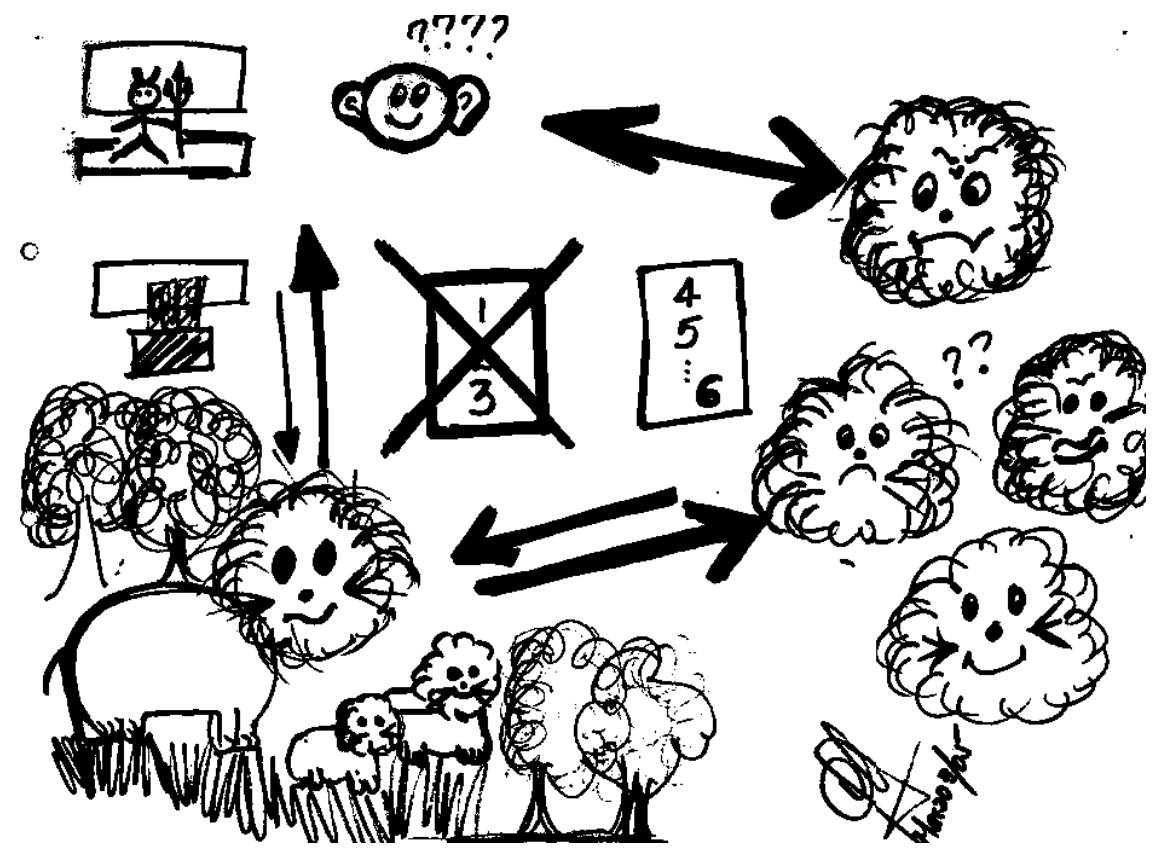

Figure 2. Example of a rich picture 


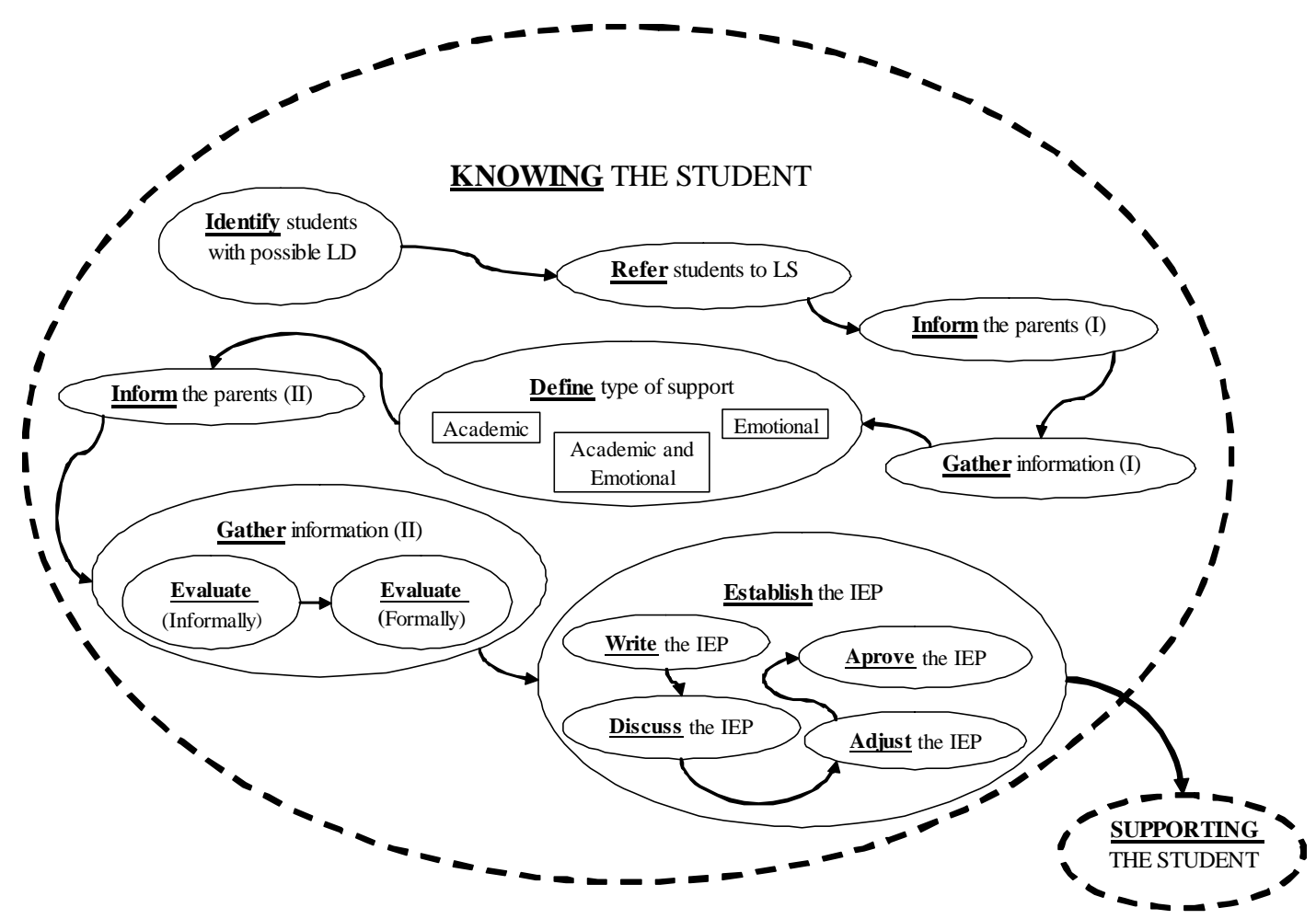

Figure 3. Conceptual model for Supporting the student 